\title{
Futures Trading Activity and Commodity Cash Price Volatility
}

\author{
Jian Yang, R. Brian Balyeat and David J. Leatham*
}

\begin{abstract}
This paper examines the lead-lag relationship between futures trading activity (volume and open interest) and cash price volatility for major agricultural commodities. Granger causality tests and generalized forecast error variance decompositions show that an unexpected increase in futures trading volume unidirectionally causes an increase in cash price volatility for most commodities. Likewise, there is a weak causal feedback between open interest and cash price volatility. These findings are generally consistent with the destabilizing effect of futures trading on agricultural commodity markets.
\end{abstract}

Keywords: agricultural commodity, futures trading, cash price volatility, GARCH, generalized forecast error variance decomposition

\section{INTRODUCTION}

The effect of futures trading on cash price volatility has long been discussed. As summarized in Kamara (1982), earlier empirical studies found that the introduction of commodity futures trading generally reduced or at least did not increase

\footnotetext{
* The first author is from the Department of Accounting, Finance and Information Systems Prairie View A\&M University. The second author is from the Department of Finance, Xavier University. The third author is from the Department of Agricultural Economics, Texas A\&M University. An earlier version of this paper was presented at the 2002 Financial Management Association annual meeting in San Antonio, Texas, USA. The authors would like to thank FMA session participants for suggestions and Jin Zhang for capable research assistance. In particular, they gratefully acknowledge very helpful comments from an anonymous referee that significantly improved the paper. Jian Yang also acknowledges support from the Tom Slick Research Fellowship at Texas A\&M University when this project was initiated. (Paper received October 2002, revised and accepted November 2003)
}

Address for correspondence: Jian Yang, Department of Accounting, Finance and Information Systems, Prairie View A\&M University, Prairie View, TX 77446, USA. e-mail: jian_yang@pvamu.edu 
cash price volatility. Accounting for time-varying patterns of price volatility (which is often modeled as a GARCH process), more recent works (e.g., Antoniou and Foster, 1992; and Gulen and Mayhew, 2000) generally did not alter this conclusion. However, these studies usually compare cash market volatility before and after the introduction of futures trading; thus, they implicitly focus on the paradigm of introducing futures trading.

Recently, some researchers (Figlewski, 1981; Bessembinder and Seguin, 1992; Darrat and Rahman, 1995; Chen, Cuny and Haugen, 1995; Chatrath, Ramchander and Song, 1996; Adrangi and Chatrath, 1998; and Gulen and Mayhew, 2000) investigated a related but different question: how does the level of futures trading activity (volume and/or open interest) affect cash market volatility? These studies may provide a more interesting perspective than earlier papers, as earlier studies focused mostly on having or not having additional speculation from the introduction of a futures market. However, according to Stein (1987), the impact of more or less speculation from an established futures trading on cash market volatility is far more relevant to the real world than to the introduction of a futures market. This hypothesis can be explored by examining the relationship between the level of futures trading activity and cash price volatility.

Specifically, Figlewski (1981) found a positive contemporaneous association between GNMA cash price volatility and futures trading activity (both trading volume and open interest). Similarly, Chen, Cuny and Haugen (1995) and Bessembinder and Seguin (1992) documented a positive contemporaneous association between stock index volatility and unexpected components of futures trading activity. Nevertheless, as pointed out by Figlewski (1981, p. 455), the contemporaneous relationship as evidence for a destabilizing effect of futures trading should be interpreted with caution, as there exists the possibility of reverse causation (i.e., cash price volatility induces futures trading activity). More recently, researchers extended this line of work to include causality analysis, and the findings are mixed. Darrat and Rahman (1995) reported no evidence for the causality running from the S\&P 500 futures trading activity (both volume and open interest) to cash price volatility. By contrast, Chatrath, Ramchander and Song (1996) argued that 
currency futures trading activity (trading volume) had a significant positive (i.e., destabilizing) causal impact on the cash price volatility, with a weaker negative causal influence from the spot exchange rate volatility on futures trading activity. Adrangi and Chatrath (1998) reported that no causality existed between cash market volatility and the open interest position of large hedgers. They also found that an increase in the unexpected component of open interest positions of large speculators and small traders caused higher cash price volatility, which was interpreted as evidence of a destabilizing effect.

The purpose of this paper is to empirically examine lead-lag relationships between the level of futures trading activity and cash price volatility in commodity futures markets. This study contributes to the literature in three aspects. First, it documents new empirical regularities on the causal relationship between commodity futures trading activity and cash price volatility. As reviewed above, previous works on this line of research focused on financial futures markets and little work has been done on commodity futures markets. The findings on financial futures markets cannot automatically be applied to commodity markets, as cash market characteristics for financial instruments and for commodities may be quite different (see Figlewski, 1981, p. 450; and Kamara, 1993). In particular, compared to commodity cash markets, many financial cash markets are highly developed, integrated, and already permit a significant amount of hedging and risk transfer through forward contracts. Second, in addition to Granger causality tests widely used in previous studies, forecast error variance decompositions are conducted to shed more light on the concerned causal relationship. Many researchers (Sims, 1972, p. 545; Sims, 1980, p. 20; and Abdullah and Rangazas, 1988, p. 682) argue that Granger causality tests only allow for statistical significance of economic variables in explaining a dependent variable, and such tests could yield misleading inferences. Instead, forecast error variance decompositions allow for the economic significance of the variables in explaining a dependent variable. Also, instead of the traditional orthogonalized forecast error variance decomposition (Sims, 1980), this study employs generalized forecast error variance decomposition (Pesaran and Shin, 1998), which is able to circumvent the problem of sensitivity of forecast error variance decompositions 
to the ordering of variables in the system and results in a unique solution. The method has not been commonly applied in financial research, with the recent exceptions of Yang, Min and Li (2003) and Wang, Kutan and Yang (2004). Finally, this study extends the literature by examining both the lead-lag relationship between cash price volatility and futures trading volume and between cash price volatility and open interest. Few of the previous studies examined both the lead-lag relationship between cash price volatility and futures trading volume and the relationship between cash price volatility and open interest. Compared to previous works, this study creates a more complete picture concerning the debate over the stabilizing or destabilizing effects of futures trading. ${ }^{1}$

\section{EMPIRICAL METHODOLOGY}

Following the literature (Antoniou and Foster, 1992; and Gulen and Mayhew, 2000), cash price volatility is modeled as a $\operatorname{GARCH}(1,1)$ process, which addresses the well-documented time-varying pattern of commodity cash price volatility. Futures volume and open interest should be decomposed into expected and unexpected components, as pointed out by Bessembinder, Chan and Seguin (1996). Only the unexpected components of futures trading activity are relevant to the study. Based on the rational expectations theory, the information embedded in the expected components of futures trading activity should already be (to a great extent) reflected in the cash price. Again, following the literature (Bessembinder and Seguin, 1992 and 1993; and Bessembinder, Chan and Seguin, 1996), this study uses 100-day and 21-day moving averages of volume (or open interest) as the expected component and the difference between actual volume (or open interest) and the expected component as the unexpected component. However, if the effect of an economic shock on these markets is highly persistent, expectations formed on the 100-day or 21-day moving average may or may not be

1 Typically, trading volume is used as the indicator of futures trading activity, and there is a large body of literature examining how futures trading volume as a proxy of information is related to price volatility (see Karpoff, 1987). In contrast, relatively little research has used the existence of open interest data (see Bessembinder and Seguin, 1993). 
able to 'whiten' the unexpected component. Thus, significant autocorrelation might still exist in the daily series of unexpected futures trading activity because a large number of trading days (beyond the expected horizon of 100 or 21 trading days) could be needed for full incorporation of the information from an economic shock into these series. In fact, there is prevalent evidence that these three variables (cash price volatility, futures trading volume, and open interest) are highly autocorrelated and may even contain a unit root (see, e.g., Bessembinder and Seguin, 1993). Allowance for the high autocorrelation problem is important and is addressed in this study (to be discussed below).

This study examines the lead-lag relationship between (unexpected) futures trading activity and cash price volatility using two econometric methods. The first method is the Granger (1969) causality test. To test Granger causality running from $X$ to $Y$ (i.e., $X \rightarrow Y$ ), the following specification is used:

$$
\begin{gathered}
Y_{t}=\alpha_{0}+\sum_{i=1}^{p} \beta_{i} Y_{t-i}+\varepsilon_{0 t}, \\
Y_{t}=\alpha_{1}+\sum_{i=1}^{p} \beta_{i} Y_{t-i}+\sum_{j=1}^{q} \gamma_{j} X_{t-j}+\varepsilon_{1 t},
\end{gathered}
$$

where $\varepsilon_{0 t}$ and $\varepsilon_{1 t}$ are white noise residuals. The lag $p$ can be chosen to be arbitrarily large so that only innovation in $Y$, which cannot be explained by its own history, is relevant and there is little remaining autocorrelation in equation (1). In this study, the lag of $p=5$ is used consistently in the context of equations (1) and (2) when $Y$ represents the (unexpected) trading volume or open interest (based on the 100-day or 21-day moving average). The lag of $p=10$ is used when $Y$ represents cash price volatility. The lag structure in $p$ is chosen to adequately address any autocorrelation problems. Given the lag $p$, the lag $q$ is chosen by applying the rule of minimization of Schwarz information criterion (SBC).

The direct Granger test based on equations (1) and (2) is equivalent to testing the following null hypothesis:

$$
\gamma_{1}=\gamma_{2}=\ldots=\gamma_{q}=0,
$$


which usually can be conducted using the $F$-statistic:

$$
F=\frac{\left(\mathrm{SSE}_{1}-\mathrm{SSE}_{2}\right) / q}{\mathrm{SSE}_{1} /(N-p-q-1)},
$$

where $\mathrm{SSE}_{1}$ and $\mathrm{SSE}_{2}$ are the sum of squared errors from least squares regressions on equations (1) and (2). Following Bessembinder, Chan and Seguin (1996), the estimation with the appropriate heteroscedasticity and autocorrelationconsistent covariance matrix (Newey and West, 1987) is applied to equations (1) and (2). ${ }^{2}$ This application can address any possible (higher order) conditional heteroscedasticity (and possibly remaining autocorrelation) problems of the three concerned variables, particularly when $Y$ represents cash price volatility. Thus, the appropriate $\chi^{2}$ statistic is used (instead of the $F$ statistic) to test the above null hypothesis in equation (3).

The second method used in this study is forecast error variance decompositions. As emphasized in the literature (Sims, 1972, p. 545; Sims, 1980, p. 20; and Abdullah and Rangazas, 1988, p. 682), it may be misleading to rely solely on the statistical significance of economic variables as determined by the Granger causality tests. Specifically, some variables may not be statistically significant in explaining a dependent variable for various reasons (e.g., instability) but may be economically significant (which may be captured by the magnitudes of coefficient estimates). These variables, which may be statistically insignificant but economically significant, should not be ignored in the model specification. Based on this very consideration, Sims (1980) recommends that forecast error variance decomposition (or impulse response analysis) should be used to model the relationship between economic variables, as it allows for economic significance of the selected variables. Thus, according to Sims (1980), forecast error variance decomposition may produce some insights beyond the Granger causality tests, such as the strength of a causal relationship between economic variables in addition to the direction of such a casual relationship.

2 See Booth et al. (1997, p. 1570) for more technical details on how the heteroscedasticity and autocorrelation-consistent covariance matrix is estimated and used to conduct hypothesis testing and inference in a similar setting. 
In this study, a relatively new econometric technique, generalized forecast error variance decomposition (Pesaran and Shin, 1998), is employed to better explore interrelationships between economic variables. This decomposition is motivated by the existence of strong contemporaneous correlations between the three variables (Figlewski, 1981; Bessembinder and Seguin, 1992; and Chen, Cuny and Haugen, 1995). In such cases, it is well known that the traditional orthogonalized forecast error variance decomposition, based on the widely used Choleski decomposition, is sensitive to the ordering of the variables. By contrast, generalized forecast error variance decomposition is invariant to the ordering of the variables, thus, it is uniquely determined.

Let $Z_{t}$ denote a vector that includes multiple economic variables. The vector $Z_{t}=\left(X_{t}, Y_{t}\right)^{\prime}$ can be modeled as an infinite moving average process:

$$
Z_{t}=\sum_{i=0}^{\infty} C_{i} \varepsilon_{t-i}, \quad t=1,2, \ldots, T .
$$

As demonstrated in Pesaran and Shin (1998), the generalized forecast error variance decomposition for the vector $Z_{t}$ is given by:

$$
\theta_{i j}(n)=\frac{\sigma_{i i}^{-1} \sum_{l=0}^{n}\left(e_{i}^{\prime} C_{l} \Sigma e_{j}\right)^{2}}{\sum_{l=0}^{n}\left(e_{i}^{\prime} C_{l} \Sigma C_{l}^{\prime} e_{i}\right)}, \quad i, j=1,2, \ldots, m,
$$

where $\sigma_{j j}$ is $j j^{\text {th }}$ element of the residual variance-covariance matrix $\Sigma$ of the vector $Z_{t}, e_{j}$ is a $m \times 1$ vector with unity at the $j^{\text {th }}$ row and zeros elsewhere, and $n$ is the number of steps ahead. The generalized forecast error variance decomposition reveals to what extent variation of a certain economic variable can be explained by innovations from other economic variables in the system. It can be used to measure the relative importance of other economic variables in influencing a particular economic variable.

\section{DATA}

As described in Table 1, the data consist of daily cash closing prices, daily futures settlement prices, total futures trading volume (TV), 


\section{Table 1}

Description of Data

\begin{tabular}{lll}
\hline Commodity & \multicolumn{1}{c}{ Cash Market } & \multicolumn{1}{c}{ Futures Market } \\
\hline Corn & No. 2 yellow corn in Chicago & CBT corn futures \\
Soybeans & No. 1 yellow soybeans in Chicago & CBT soybeans futures \\
Sugar & Sugar, cane, raw, world, fob & CSCE sugar (world) futures \\
Wheat & Hard wheat in Kansas City & KCBT wheat futures \\
Cotton & $\begin{array}{l}\text { 1 1/16 string low-middle cotton in } \\
\text { Nemphis }\end{array}$ & NYE cotton futures \\
Hog & $\begin{array}{l}\text { Hogs in Omaha/lean hog price } \\
\text { index }\end{array}$ & CME hogs futures \\
Cattle & Steers in Omaha & CME live cattle futures \\
\hline
\end{tabular}

and total futures open interest (OI) for corn, soybean, wheat, cotton, sugar (world), hogs, and live cattle futures. ${ }^{3}$ All data are provided by Datastream. The whole sample period of January 1, 1992 to December 31, is divided into two subperiods: the first period of January 1, 1992 to December 31, 1995, and the second period of January 1, 1997 to December 31, 2001. Such a division is necessary to address the structural change in the data. In particular, the 1996 Federal Agricultural Improvement and Reform (FAIR) Act (effective April 4, 1996) was considered a watershed change in US agricultural policy as it brought virtually full flexibility to US crop production for the first time. By contrast, until 1990 there was very limited production flexibility. Another reason for this division of the sample period is a contract specification change of hog futures. Beginning with the February 1997 contract, lean hog futures contracts replaced live hog futures contracts, and a new cash settlement procedure replaced the previous physical delivery settlement procedure. If 1996 is included in the sample, structural changes may force us to address the problems of coefficient estimate instability. In general, the

3 As correctly pointed out by the referee, if the cash and futures data are not recorded at the same time, this could affect the lead-lag relationship between them. The information from Datastream shows that both cash and futures prices are recorded at the end of the trading day. This question is also addressed by investigating the relationships between the same set of variables at the weekly instead of the daily frequency. When the data is sampled at the weekly frequency rather than the daily frequency, the asynchronous trading problem is mitigated. The results based on the weekly data (available upon request from the authors) are similar to what is reported in the text based on the daily data. 
problem might be addressed by adding dummy variables for every coefficient estimate in equations (1) and (2). However, this greatly complicates the causality tests. By contrast, the division of the sample period can serve as a robustness check on the causal patterns.

\section{EMPIRICAL RESULTS}

Similar to previous studies (e.g., Bessembinder and Seguin, 1992 and 1993; and Bessembinder, Chan and Seguin, 1996), the augmented Dickey-Fuller tests (not reported here) show that both expected and unexpected components of volume, open interest, and cash price volatility for all commodities are stationary. Bivariate causality analysis [based on equations (1), (2), (3) and (4)] is conducted between both cash price volatility and futures trading volume and cash price volatility and open interest to facilitate comparison of results between this study and previous studies. Most of the previous studies conducted analysis in similar bivariate contexts. In addition, if there exists another important causal variable that is not included in the analysis, bivariate causality analysis might actually investigate prima facie causality as distinct from a true causal relationship. The prima facie causality is a necessary condition, although not a sufficient condition, for true causality. Thus, testing for prima facie causality may be considered the first major step towards concluding causality between two variables. In this study, further trivariate analysis, with the added variable of futures price volatility, confirms that the bivariate causality results provide reliable inferences in the context of causal relationships between futures trading activity and cash price volatility. The econometric analysis based on both the 100-day and 21-day moving average is conducted. The results based on the 21-day moving average strongly confirm the results based on the 100-day moving average. Hence, only the results based on the 100-day moving average are reported below. ${ }^{4}$

4 Following the existing literature (Bessembinder and Seguin, 1992 and 1993; and Bessembinder, Chan and Seguin, 1996), the measurement of expectations as moving averages in this study is calculated over 21-day and 100-day intervals. As pointed out by the referee, such a way of measurement might be casual. Nevertheless, the results based on two ad hoc periods of time (21-day and 100-day) are quite similar. 
The bivariate causality test results are reported in Table 2. The lag length is determined according to the methodology set forth in the empirical methodology section. Table 2 shows parameter estimates of lagged $X$ 's [i.e., $\gamma_{j}(j=1, \ldots, q)$ in equation (2)] but not parameter estimates of lagged $Y^{\prime}$ s, which are not informative for the purpose of Granger causality tests. Table 2 also shows standard errors and $R$-squareds for each regression, as defined in equation (2). In most cases, $R$-squareds for these regressions are reasonably high, suggesting a good fit for the relevant regression. The statistical significance of individual parameter estimates is also denoted based on heteroscedasticity and autocorrelation-consistent $t$-ratios. In most cases where Granger causality running from unexpected trading volume to cash price volatility (UTV $\rightarrow \mathrm{CV}$ ) is tested, at least one parameter is statistically significant. This finding provides preliminary evidence for such causality. By contrast, in most cases where Granger causality in the other direction $(\mathrm{CV} \rightarrow$ UTV) is tested, there is no statistically significant parameter in the relevant regression. In addition, the sign of statistically significant parameters often determines the sign of such Granger causality tests (to be discussed below), although it may not be clear in the cases of multiple statistically significant parameters with opposite signs.

More formally, Granger causality tests are conducted through joint hypothesis testing on significance of all $\gamma_{j}$ parameters, as defined in equations (3) and (4). The joint testing is particularly revealing in cases where multiple lags exist for $X$ and collinearity might lead to insignificance for all individual parameter estimates (e.g., corn and hog in the test of CV $\rightarrow$ UTV in the period of 1992-1995 as shown in Table 2) or in cases where there are multiple statistically significant parameters with opposite signs. Recall that the heteroscedasticity and autocorrelationconsistent covariance matrix (Newey and West, 1987) is applied in estimation and inference; thus, the appropriate test statistics for such joint hypothesis tests are $\chi^{2}$ statistics. The $p$-values for the corresponding $\chi^{2}$ statistics are also reported in Table 2. If the reported $p$-values are larger than the 0.05 significance level, the null hypothesis of no causality with the projected direction cannot be rejected. The sign of such Granger causality is only reported if the joint hypothesis is significant at the 0.05 


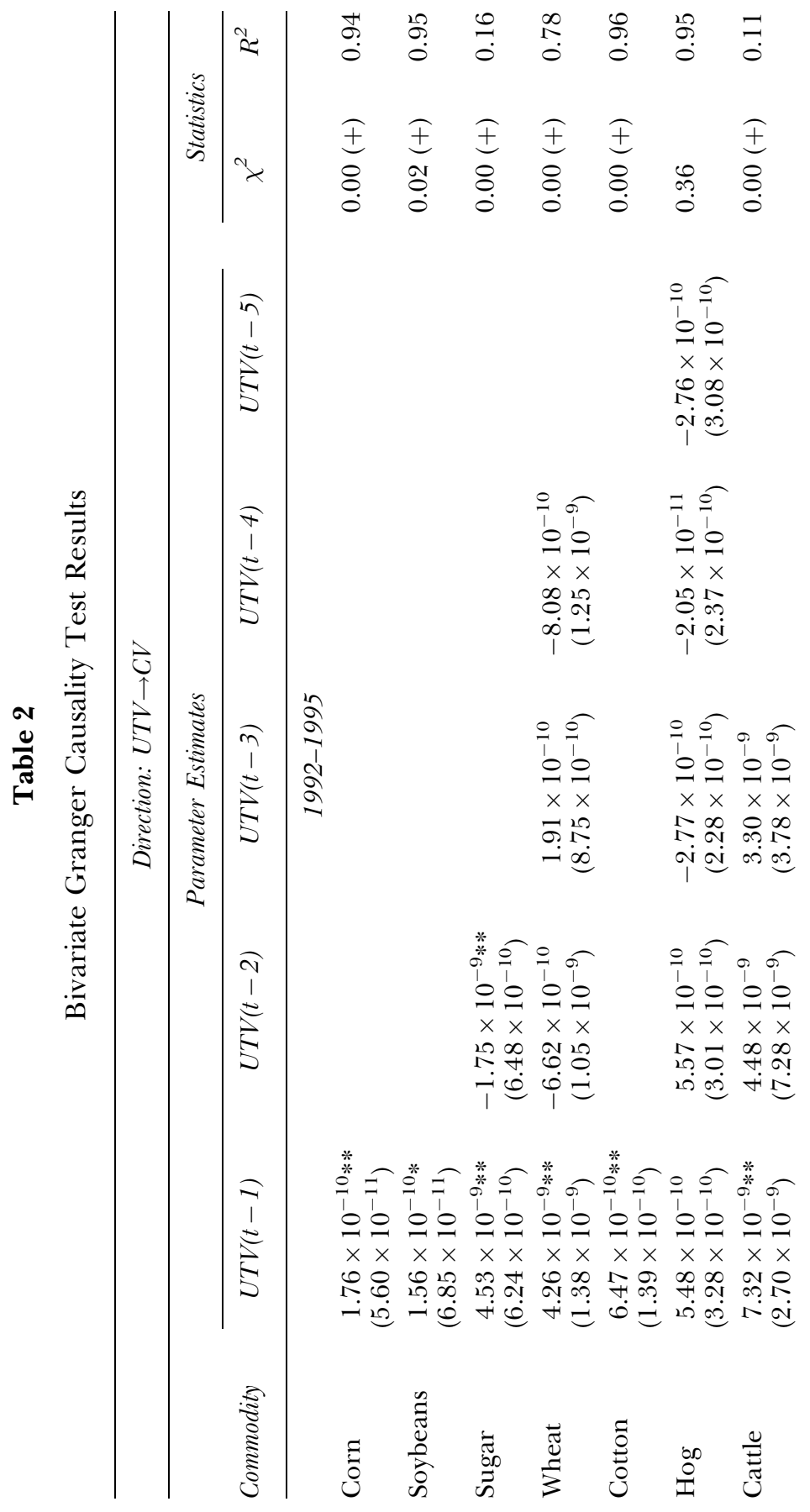




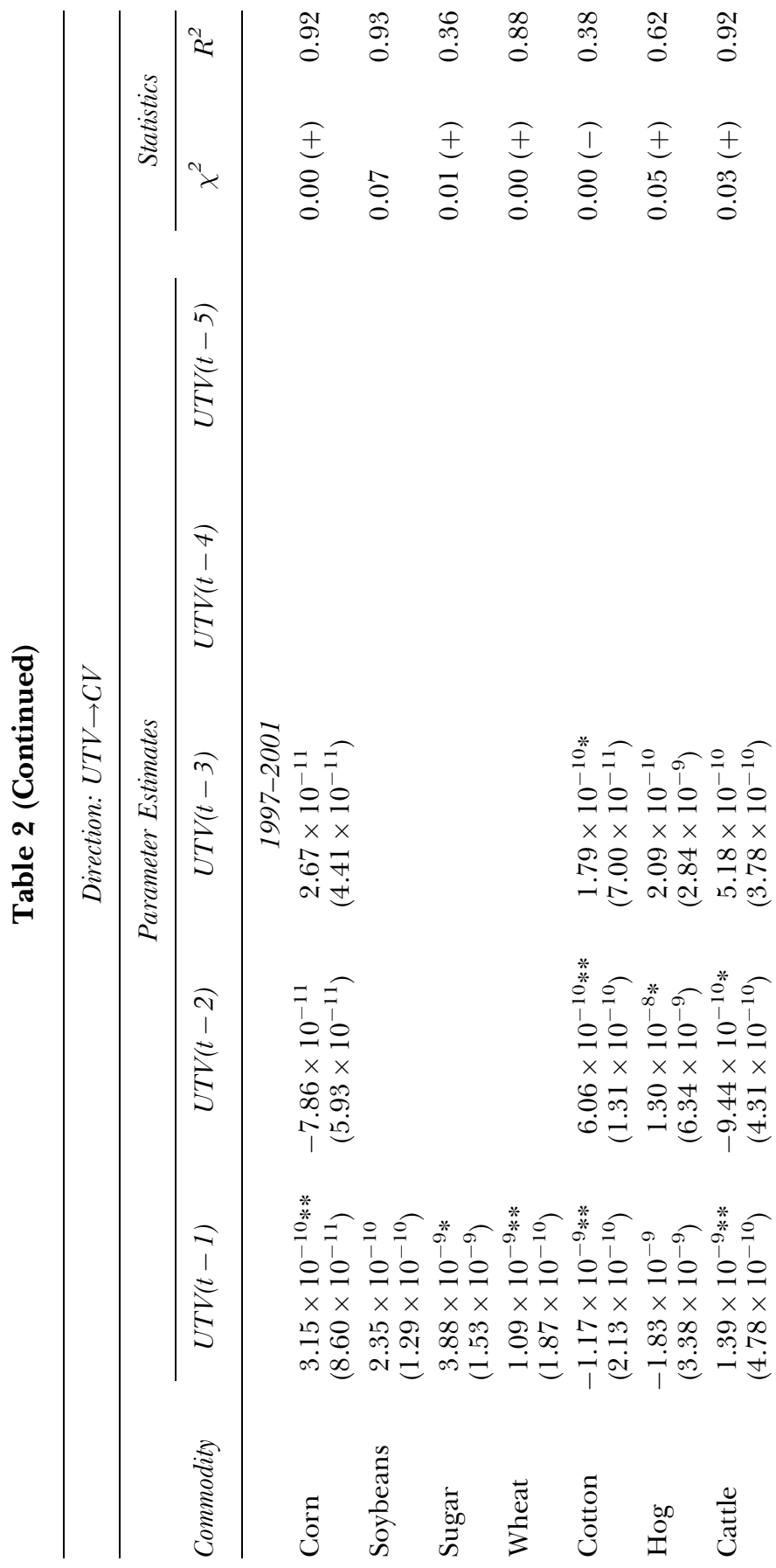




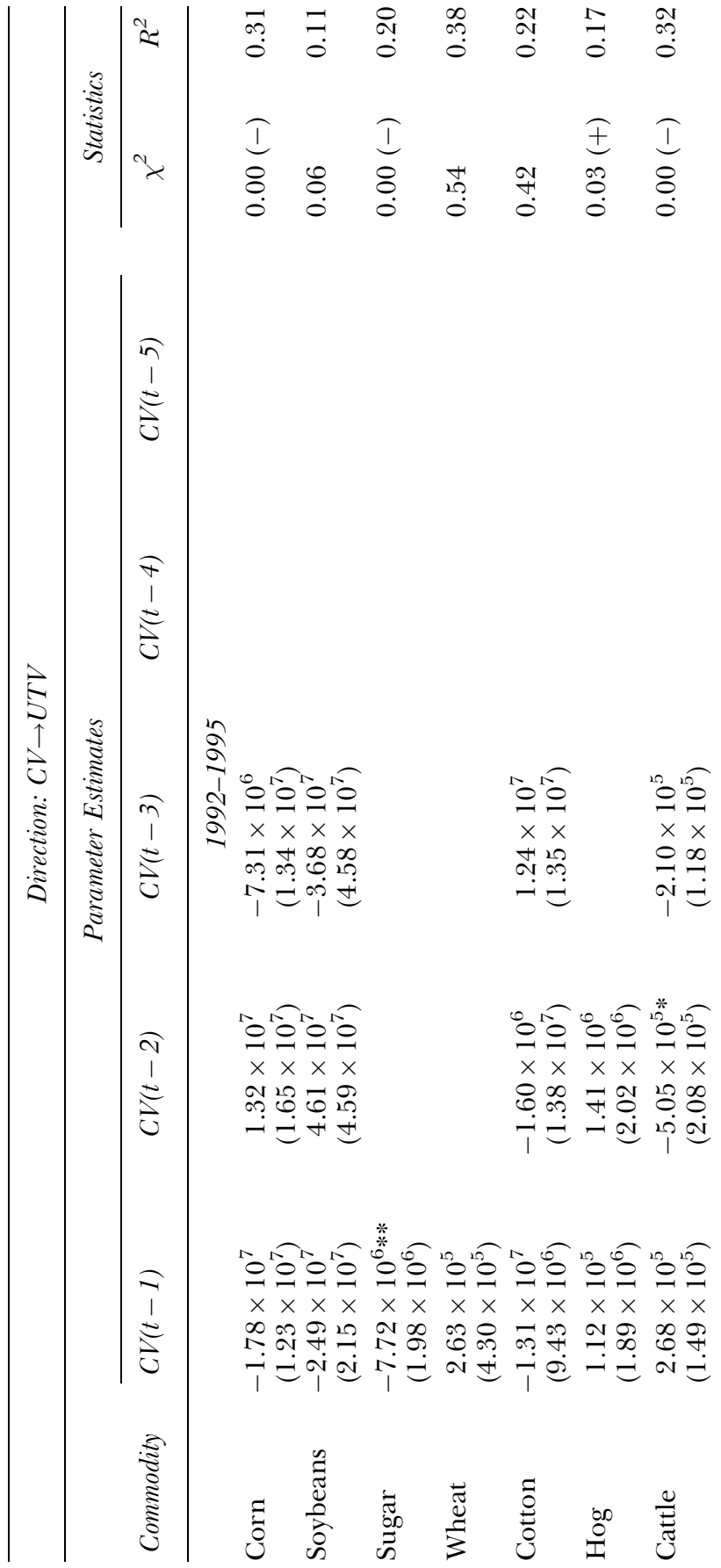




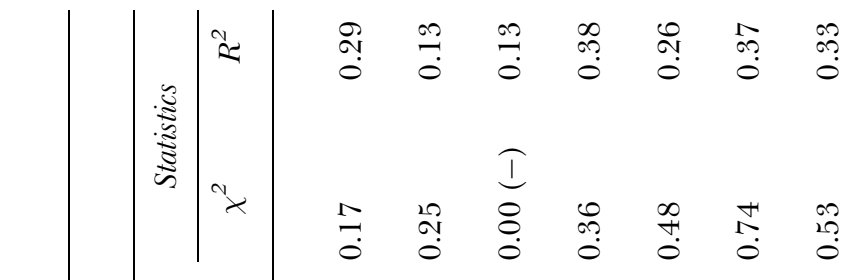

$$
\begin{aligned}
& \text { in } \\
& \text { 旅 } \\
& \text { 赔 }
\end{aligned}
$$

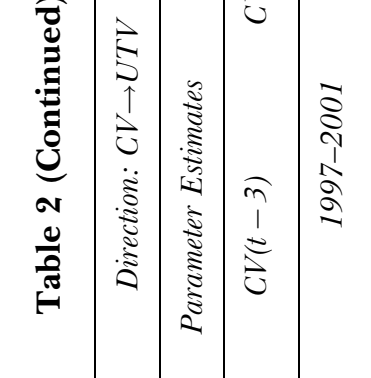

$$
\begin{aligned}
& \underset{\sim}{1}
\end{aligned}
$$

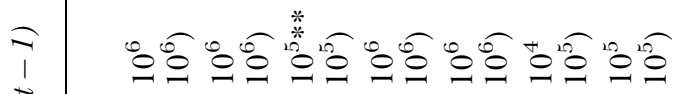

$$
\begin{aligned}
& \approx \times \times \times \times \times \times \times \times \times \times \times
\end{aligned}
$$

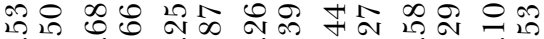

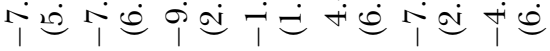

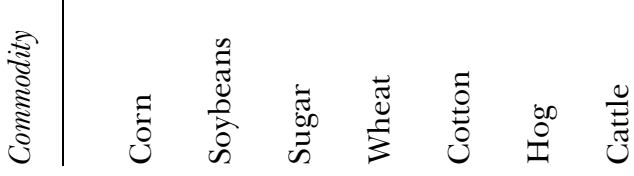




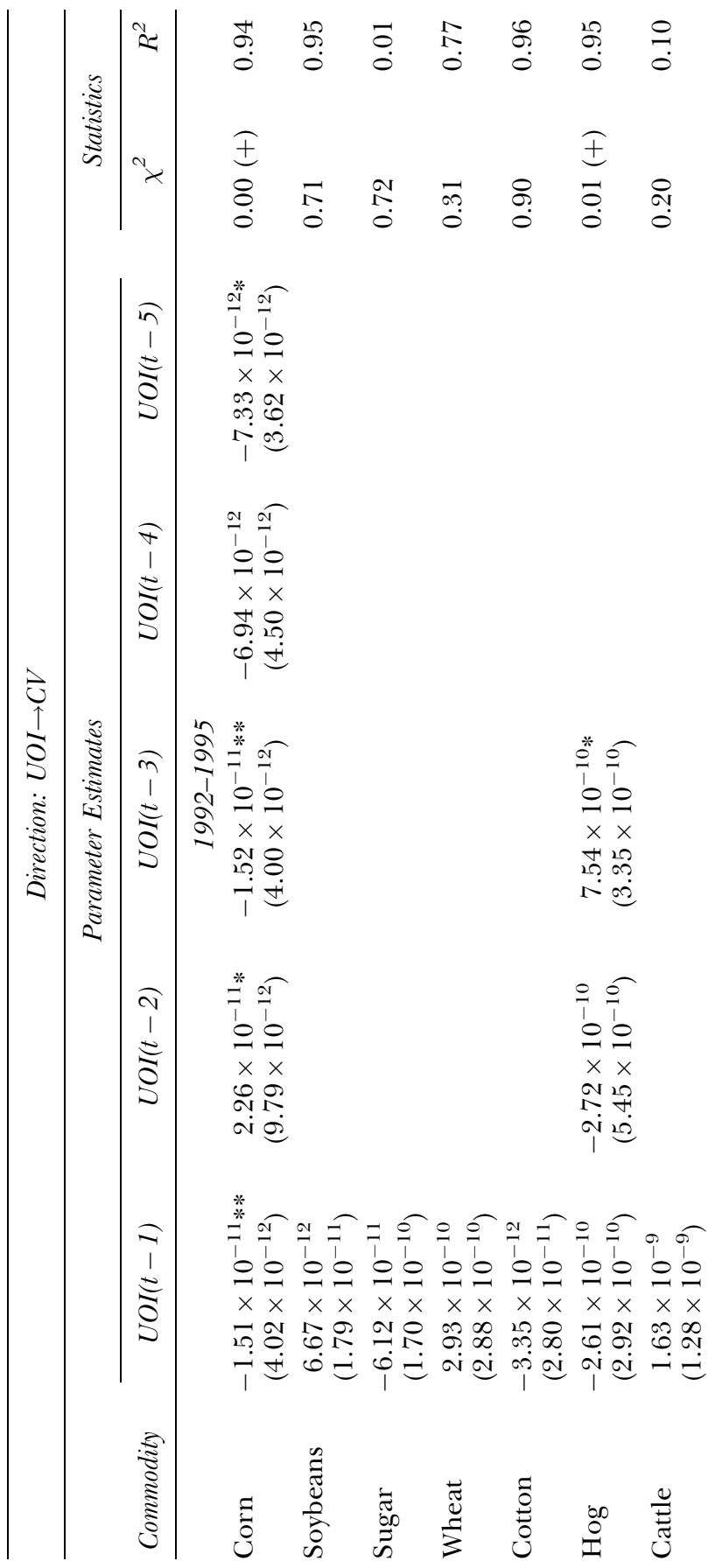




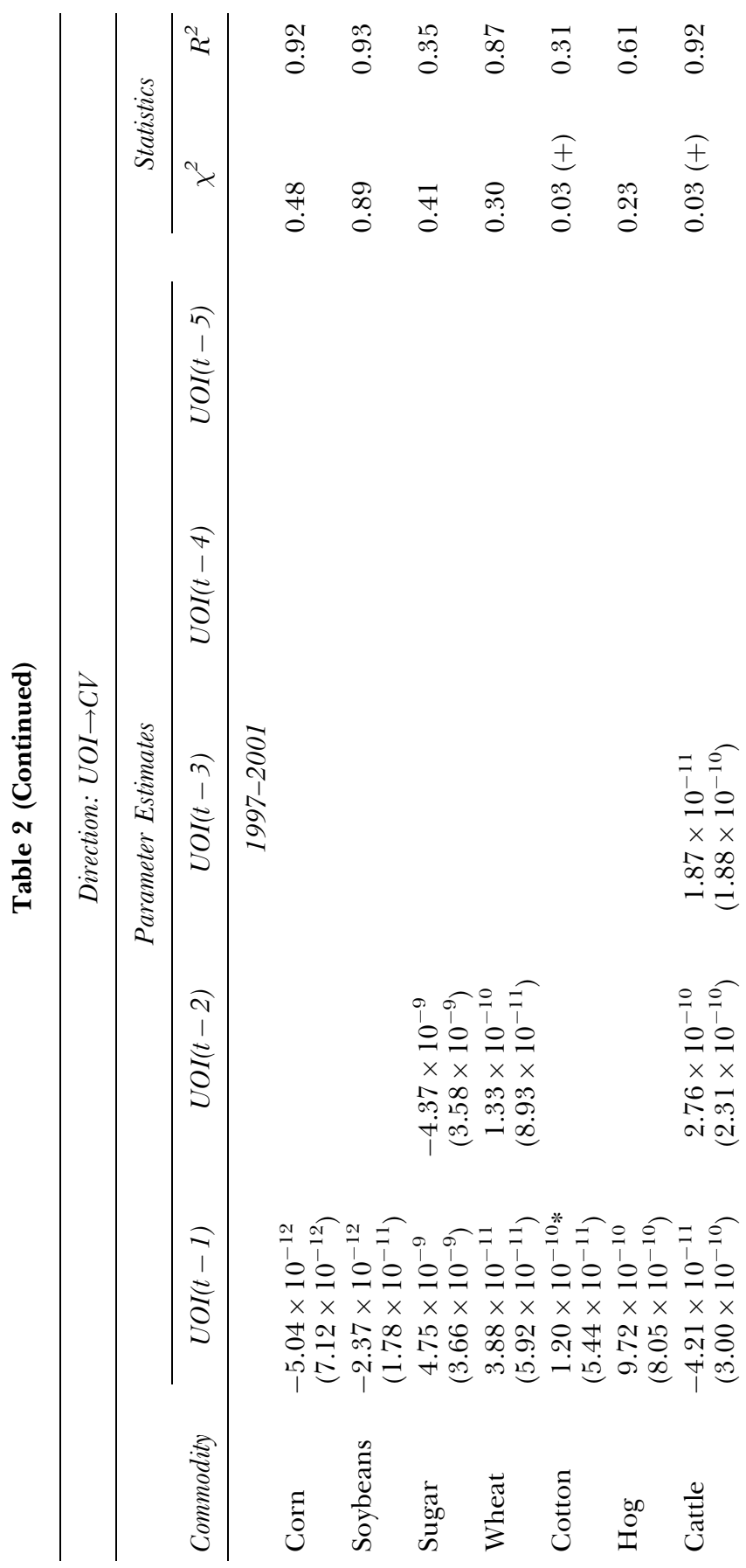




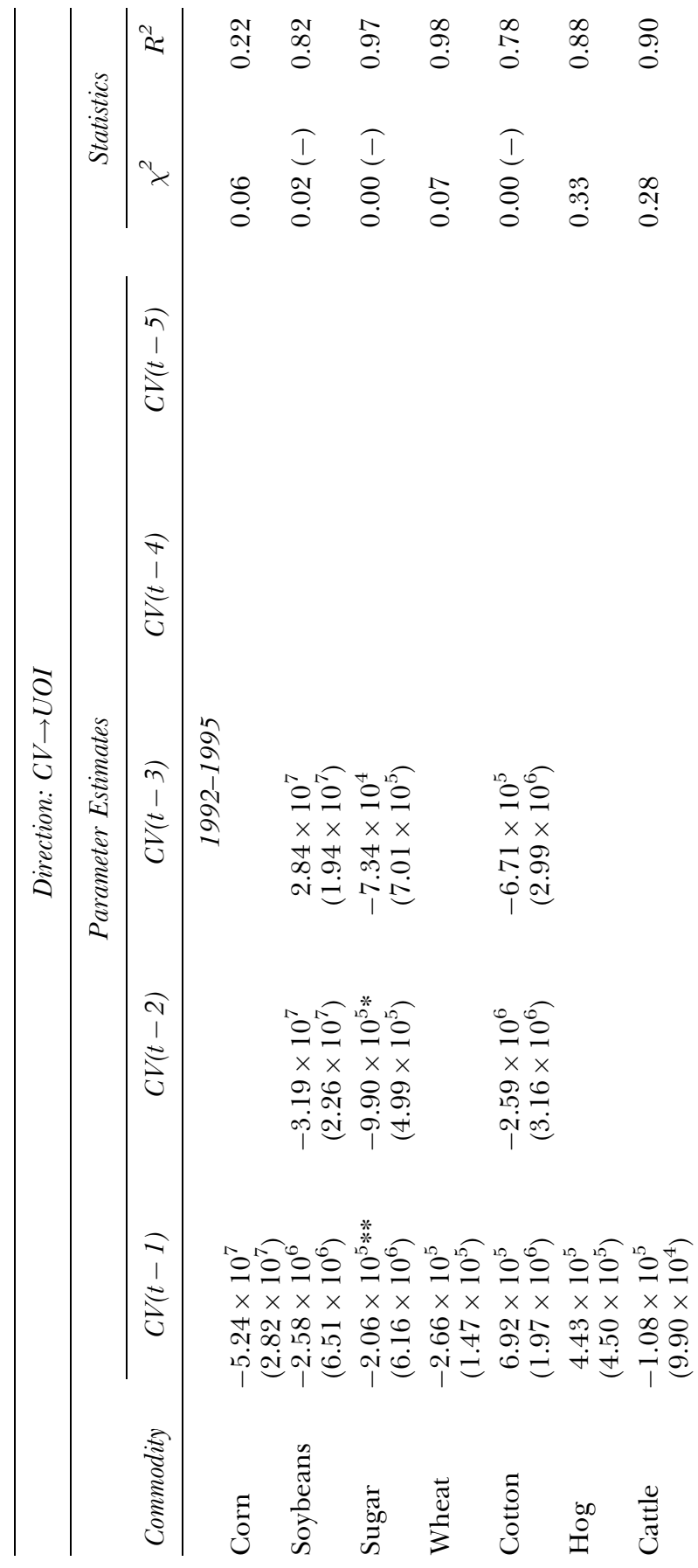




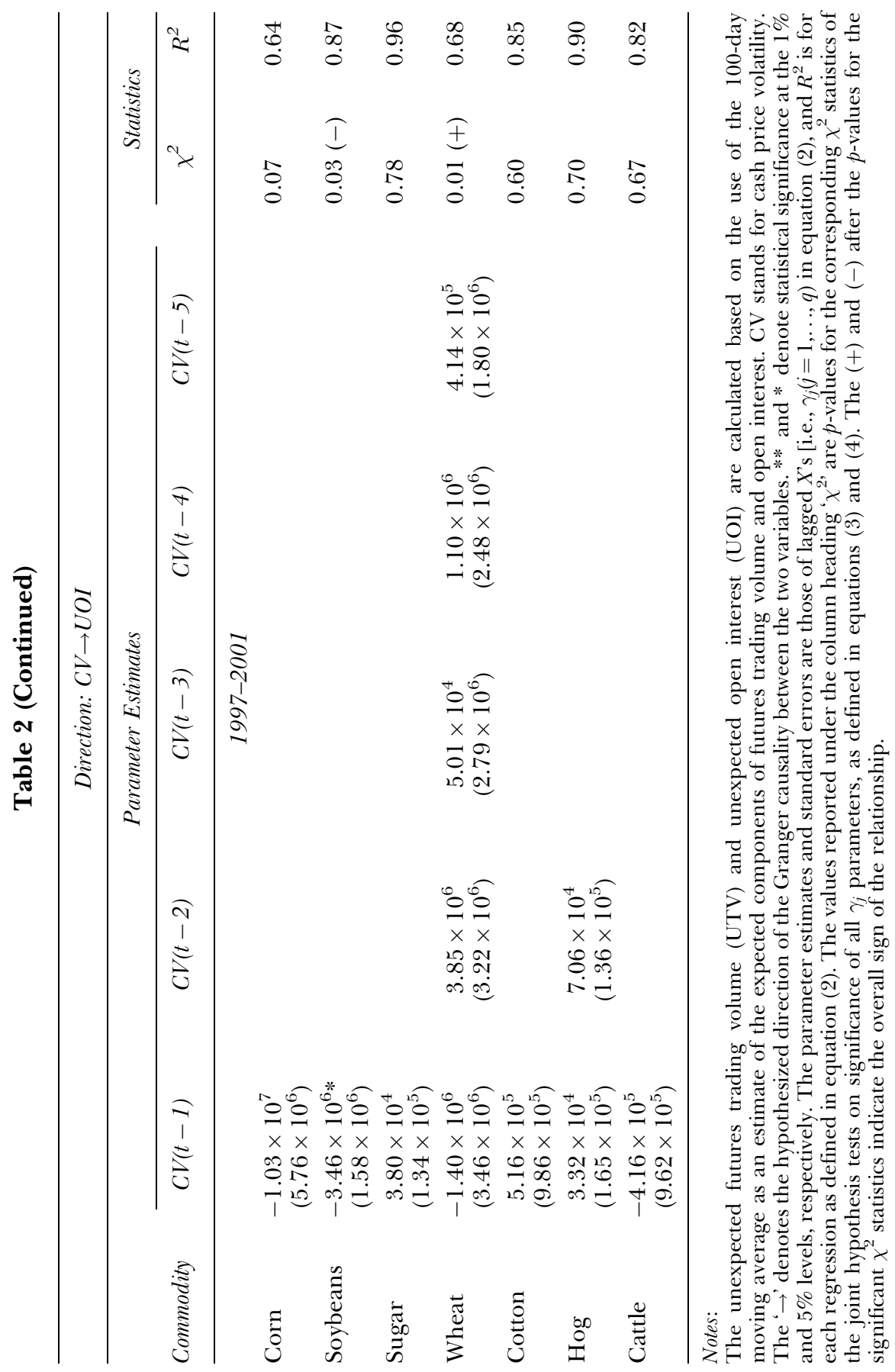


significance level. In the literature of futures markets, futures market participants are traditionally classified as either hedgers or speculators. The following interpretation follows the convention that daily futures volume primarily reflects movements in speculators' activity while futures open interest primarily reflects hedgers' activity (Working, 1962; Peck, 1980; Leuthold, 1983; Bessembinder and Seguin, 1993; and Kamara, 1993).

With respect to the lead-lag relationship between cash price volatility and futures trading volume, several points are readily apparent from Table 2. First, at any conventional significance level, unexpected futures trading volume causes cash price volatility for all seven commodities in both subperiods, except for hogs in the first subperiod and soybeans in the second subperiod. This result is consistent with the findings of Chatrath, Ramchander and Song (1996) on currency futures but contradictory to the findings of Darrat and Rahman (1995) on S\&P 500 index futures. By contrast, cash price volatility causes unexpected futures trading volume for four of the seven commodities in the first subperiod but only one of the seven commodities in the second subperiod. As mentioned previously, the second subperiod represents a more market-oriented environment and should be given predominant consideration. Thus, it is concluded that, for most commodities (especially in the second subperiod), unexpected futures trading volume unidirectionally causes cash price volatility. Only for a storable commodity such as sugar do the results show different Granger causality patterns. For sugar, bi-directional feedback exists between cash price volatility and unexpected futures trading volume. This result stands in sharp contrast to the recent evidence that cash price volatility is a cause rather than an effect of futures trading on the S\&P 500 index market (Darrat, Rahman and Zhong, 2002).

With respect to the lead-lag relationship between cash price volatility and open interest, it is interesting to note that only a unidirectional causality pattern exists for some commodities and the direction of causality varies. In the first subperiod, unexpected open interest unidirectionally causes cash price volatility for two commodities (corn and hogs), while cash price volatility unidirectionally causes unexpected open interest for three commodities (soybeans, sugar, and cotton). In the second subperiod, unexpected open interest unidirectionally causes 
cash price volatility for two commodities (cotton and live cattle), while cash price volatility unidirectionally causes unexpected open interest for two commodities (soybeans and wheat). No unidirectional or bi-directional causality exists for the three remaining commodities in the second subperiod. In addition, as shown in further results on generalized forecast error variance decompositions, these statistically significant causal relationships between open interest and cash price volatility (revealed in Granger causality tests) are not economically significant. The bivariate results on the lead-lag relationship between cash price volatility and open interest is largely consistent with Darrat and Rahman (1995). However, these results do not provide much support for the argument in Chen, Cuny and Haugen (1995) that a change in S\&P 500 cash price volatility may cause a change in futures open interest.

The sign results on the maintained directions of causality, as reported in Table 2, reveal further insight. An increase in unexpected futures volume causes an increase in cash price volatility for (almost) all commodities. Similarly, in the cases where (unidirectional) causality runs from unexpected open interest to cash price volatility, an increase in unexpected open interest (unidirectionally) causes an increase in cash price volatility. By contrast, in the cases where causality runs from cash price volatility to either unexpected trading volume or unexpected open interest, an increase in cash price volatility usually causes a decrease in unexpected futures trading volume or in unexpected open interest. This evidence is consistent with Chatrath, Ramchander and Song (1996), as they observed a negative lagged impact of spot exchange rate volatility on futures trading volume. However, this evidence is largely contradictory to the projection of Chen, Cuny and Haugen (1995) that an increase in cash price volatility will cause an increase in futures open interest.

Based on estimated VARs in the two subperiods, the generalized forecast error variance decompositions are conducted for bivariate cases between cash price volatility and unexpected trading volume and between cash price volatility and unexpected open interest. Additionally, to check the robustness of the causality results based on bivariate analysis, generalized forecast error variance decompositions based on trivariate analysis are conducted, which includes a third variable, futures 
price volatility. The generalized forecast error variance decomposition results based on bivariate analysis yield similar inferences to the results based on trivariate analysis. Hence, only the trivariate analysis results are reported in Table 3. To conserve space, the table only provides 21-day ahead forecast error variance decompositions, which are representative of the results at other days (available upon request from the authors).

The results for two trivariate VAR models are reported in Table 3. One trivarite VAR model includes cash price volatility (CV), futures price volatility $(\mathrm{FV})$, and unexpected futures trading volume (UTV), while the other trivarite VAR model includes cash price volatility, futures price volatility, and unexpected futures open interest (UOI). As shown in Table 3, the percentage of variation in cash price volatility explained by unexpected trading volume is more than $5 \%$ for five of the seven commodities under consideration in the first subperiod [i.e., corn (6\%), soybeans (15\%), sugar $(15 \%)$, wheat $(9 \%)$ and cotton $(7 \%)]$ and six of the seven commodities in the second subperiod [i.e., corn (10\%), soybeans (10\%), wheat $(7 \%)$, cotton $(10 \%)$, hog $(6 \%)$ and live cattle $(8 \%)]$. Therefore, it is concluded that unexpected trading volume has an appreciable influence on cash price volatility for most commodities, which is consistent with Granger causality running from unexpected trading volume to cash price volatility found in Table 2. Also, the evidence for the impact of unexpected trading volume is robust against the potentially confounding influence of futures price volatility on cash price volatility. The influence of futures price volatility on cash price volatility is also noticeable for most commodities and is particularly significant for commodities such as corn $(12 \%$ in the first subperiod and $11 \%$ in the second subperiod), soybeans (25\% in the first subperiod and $27 \%$ in the second subperiod), and wheat (10\% in the first subperiod and $8 \%$ in the second subperiod).

By contrast, cash price volatility and futures price volatility account for little of the variation in the unexpected trading volume for all commodities in both subperiods. The percentage of variation in unexpected trading volume explained by cash price volatility ranges from 1 to $3 \%$ for all commodities under consideration in the first subperiod and from 0 to $1 \%$ in the second subperiod. The lack of influence of cash price volatility on unexpected trading volume is consistent with a lack of 


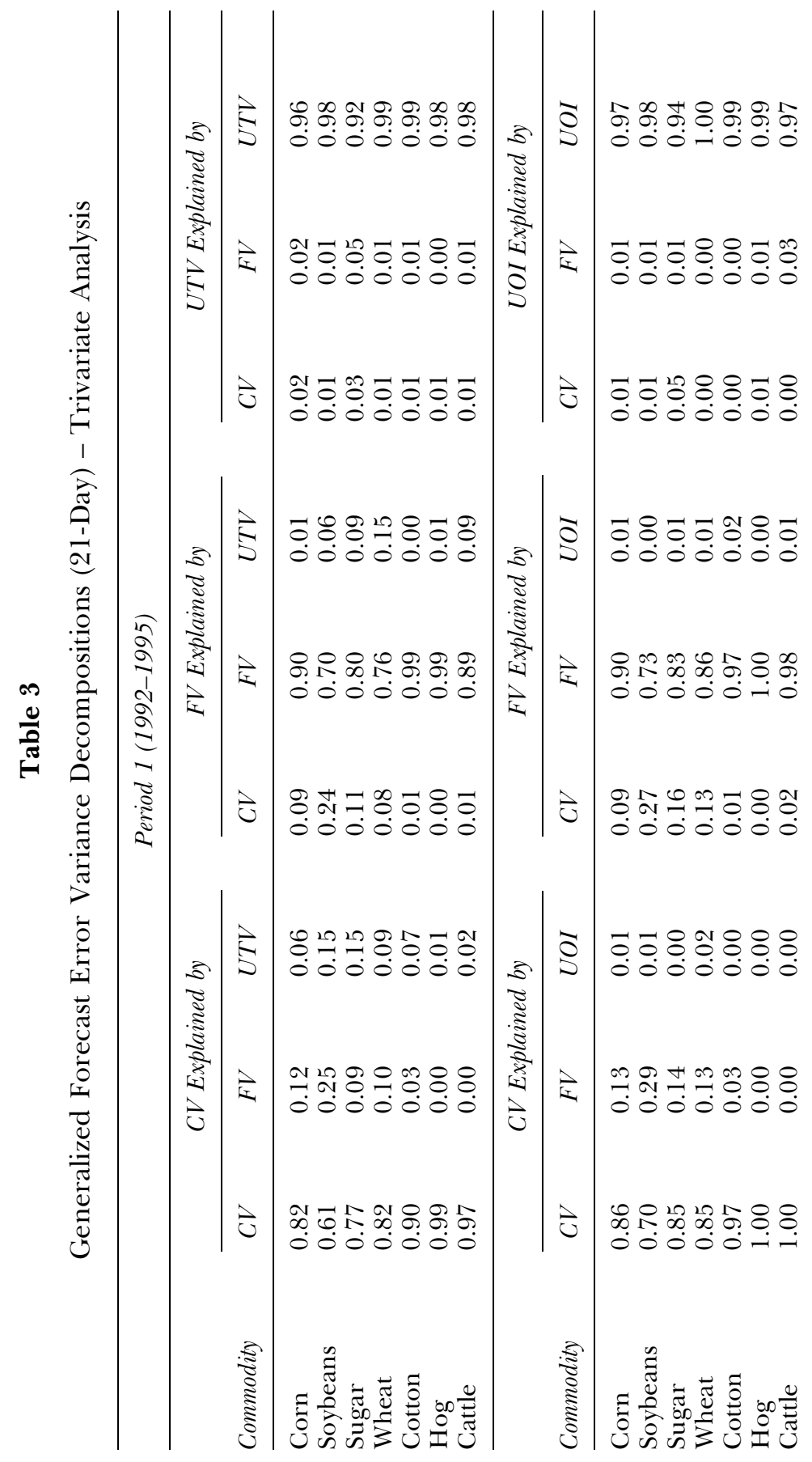




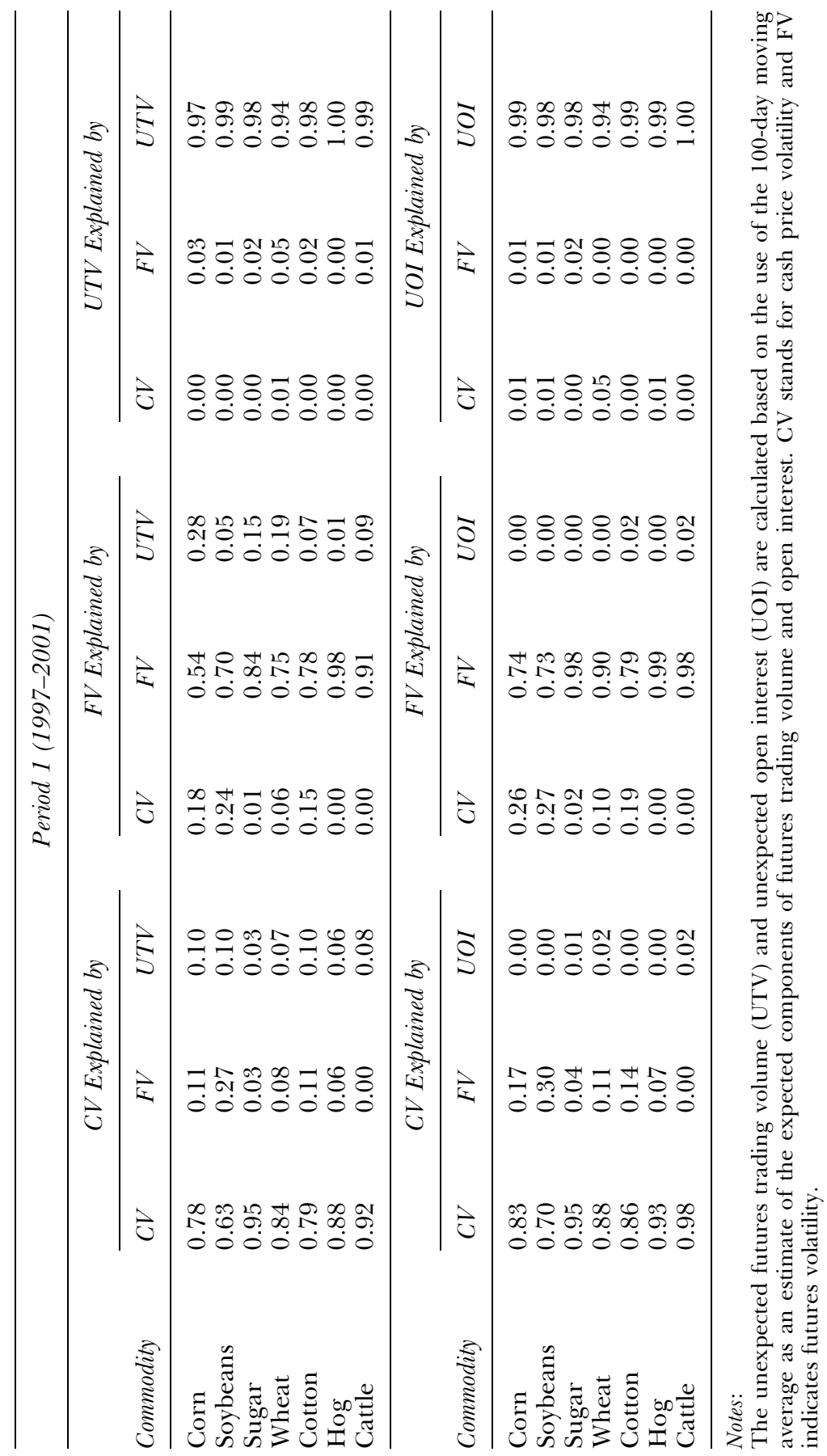


Granger causality running from cash price volatility to unexpected trading volume, as indicated in Table 2. In sum, the combined evidence from the generalized forecast error variance decompositions is supportive of unidirectional Granger causality running from unexpected trading volume to cash price volatility, as previously documented in the Granger causality tests.

The results in Table 3 also show that unexpected open interest can explain little of the variation in cash price volatility for all commodities in both subperiods. The percentage of variation in cash price volatility explained by unexpected open interest ranges from 0 to $2 \%$ for all commodities in both subperiods. The lack of influence of unexpected open interest on cash price volatility suggests that there is a lack of causality running from unexpected open interest to cash price volatility. This result mirrors the results for most of the commodities based on Granger causality tests. However, it is contradictory to the evidence for causality running from unexpected open interest to cash price volatility for a few commodities in Table 2 (i.e., corn and hogs in the first period and cotton and live cattle in the second period).

In addition, cash price volatility also accounts for little of the variations in unexpected open interest for all commodities in both subperiods, as it typically explains 0 to $1 \%$ of the variation in unexpected open interest with the highest explanatory power of $5 \%$ for sugar in the first subperiod and $5 \%$ for wheat in the second subperiod. Again, this result indicates that the evidence for causality running from cash price volatility to unexpected open interest (as found for four of the seven commodities in Table 2) may be fragile due to lack of economic significance of the causal relationships. In conclusion, the generalized forecast error variance decomposition results generally suggest that there is little causal influence between open interest and cash price volatility, which is largely consistent with Table 2.

\section{CONCLUSIONS}

This study examines the lead-lag relationships between futures trading activity (volume and open interest) and cash price volatility for major agricultural commodities. Specifically, this study finds that unexpected futures trading volume causes cash price 
volatility for most commodities, which is confirmed both by Granger causality tests and forecast error variance decompositions. The sign of the causality running from unexpected futures trading volume to cash price volatility is typically positive, which suggests that an increase in unexpected trading volume causes an increase in cash price volatility. Moreover, although Granger causality tests show that cash price volatility may cause unexpected trading volume or unexpected open interest for a few commodities and unexpected open interest may cause cash price volatility for other commodities, these causal patterns are not confirmed by forecast error variance decompositions. Thus, combining the evidence from both tests, it can be concluded that an unexpected increase in futures trading volume unidirectionally causes an increase in cash price volatility for most commodities, while there is weak causal feedback between open interest and cash price volatility.

These findings are generally consistent with the destabilizing effect of futures trading on agricultural commodity markets. This may (at least partly) explain why the criticisms of futures markets have been historically most virulent for agricultural commodities, as observed in Pashigian (1986) and Weaver and Banerjee (1990). Interestingly, the results in this paper are quite consistent with recent similar studies conducted on currency futures (Chatrath, Ramchander and Song, 1996; and Adrangi and Chatrath, 1998) but contradictory to several studies conducted on stock index futures markets (Chen, Cuny and Haugen, 1995; Darrat and Rahman 1995; and Darrat, Rahman and Zhong, 2002). Areas of interest for further research would include determining whether and how the causal relationship between futures trading activity and cash price volatility depends on different types of underlying assets or market structures. This research could also be extended to include futures markets in other developed or emerging markets.

\section{REFERENCES}

Abdullah, D.A. and P.C. Rangazas (1988), 'Money and the Business Cycle: Another Look', Review of Economics and Statistics, Vol. 70, pp. 680-85. 
Adrangi, B. and A. Chatrath (1998), 'Futures Commitments and Exchange Rate Volatility', Journal of Business Finance E Accounting, Vol. 25, pp. 501-20.

Antoniou, A. and A.J. Foster (1992), 'The Effect of Futures Trading on Cash Price Volatility: Evidence for Brent Crude Oil Using GARCH', Journal of Business Finance E Accounting, Vol. 19, pp. 473-84.

Bessembinder, H. and P.J. Seguin (1992), 'Futures Trading Activity and Stock Price Volatility, Journal of Finance', Vol. 47, pp. 2015-34.

—, (1993), 'Price Volatility, Trading Volume, and Market Depth: Evidence from Futures Markets', Journal of Financial and Quantitative Analysis, Vol. 28, pp. 21-39.

- , K. Chan and P.J. Seguin (1996), 'An Empirical Examination of Information, Differences of Opinion, and Trading Activity', Journal of Financial Economics, Vol. 40, pp.105-34.

Booth, G., M. Chowdhury, T. Martkainen and Y. Tse (1997), 'Intraday Volatility in International Stock Index Futures Markets: Meteor Showers or Heat Waves?' Management Science, Vol. 43, pp. 1564-76.

Chatrath, A., S. Ramchander and F. Song (1996), 'The Role of Futures Trading Activity in Exchange Rate Volatility', Journal of Futures Markets, Vol. 16, pp. 561-84.

Chen, N., C.J. Cuny and R. A. Haugen (1995), 'Stock Volatility and the Levels of the Basis and Open Interest in Futures Contracts', Journal of Finance, Vol. 50, pp. 281-300.

Daigler, R.T. and M.K. Wiley (1999), 'The Impact of Trader Type on the Futures Volatility-Volume Relation', Journal of Finance, Vol. 54, pp. 2297-316.

Darrat, A.F. and S. Rahman (1995), 'Has Futures Trading Activity Caused Stock Price Volatility?' Journal of Futures Markets, Vol. 15, pp. 537-57.

— Market Fluctuations: Perpetrator of Volatility or Victim of Regret?' Journal of Financial Research, Vol. 25, pp. 431-44.

Figlewski, S. (1981), 'Futures Trading and Volatility in the GNMA Market', Journal of Finance, Vol. 36, pp. 445-56.

Granger, C. (1969), 'Investigating Causal Relations by Econometric Models and Cross-Spectral Methods', Econometrica, Vol. 37, pp. 423-38.

Gulen, H. and S. Mayhew (2000), 'Stock Index Futures Trading and Volatility in International Equity Markets', Journal of Futures Markets, Vol. 20, pp. $661-85$.

Kamara, A. (1982), 'Issues in Futures Markets: A Survey', Journal of Futures Markets, Vol. 2, pp. 261-94.

- (1993), 'Production Flexibility, Stochastic Separation, Hedging, and Futures Prices', Review of Financial Studies, Vol. 4, pp. 935-57.

Karpoff, J. (1987), 'The Relation Between Price Changes and Trading Volume: A Survey', Journal of Financial and Quantitative Analysis, Vol. 22, pp. 109-26.

Leuthold, R.M. (1983), 'Commercial Use and Speculative Measures of the Livestock', Journal of Futures Markets, Vol. 3, pp. 113-35.

Newey, W. and K. West (1987), 'A Simple Positive Semi-Definite, Heteroscedasticity and Autocorrelation Consistent Covariance Matrix', Econometrica, Vol. 55, pp. 703-8. 
Pashigian, B.P. (1986), 'The Political Economy of Futures Market Regulation', Journal of Business, Vol. 59, pp. S55-84.

Peck, A.E. (1980), 'Reflections of Hedging on Futures Market Activity', in A. E. Peck (ed.), Selected Writings on Futures Markets: Basic Research in Commodity Markets (Chicago Board of Trade, Chicago, IL) pp. 305-21.

Pesaran, M.H. and Y. Shin (1998), 'Generalized Impulse Response Analysis in Linear Multivariate Models', Economic Letters, Vol. 58, pp. 17-29.

Roll, S. (1989), 'Information and Volatility: The No-Arbitrage Martingale Approach to Timing and Resolution Irrelevancy', Journal of Finance, Vol. 44, pp. 1-17.

Sims, C. (1972), 'Money, Income, and Causality', American Economic Review, Vol. 62, pp. 540-52.

(1980), 'Macroeconomics and Reality', Econometrica, Vol. 48, pp. 1-48.

Stein, J.C. (1987), 'Informational Externalities and Welfare-Reducing Speculation', Journal of Political Economy, Vol. 95, pp. 1123-45.

Weaver, R.D. and A. Banerjee (1990), 'Does Futures Trading Destabilize Cash Prices? Evidence for U.S. Live Beef Cattle', Journal of Futures Markets, Vol. 10, pp. 41-60.

Working, H. (1962), 'New Concepts Concerning Futures Markets and Prices', American Economic Review, Vol. 52, pp. 432-59.

Yang, J., I. Min and Q. Li (2003), 'European Stock Market Integration: Does EMU Matter?' Journal of Business Finance Eं Accounting, Vol. 30, pp. $1253-76$.

Wang, Z., A.M. Kutan and J. Yang (2004), 'Information Flows Within and Across Chinese Stock Markets', Quarterly Review of Economics and Finance, Vol. 44. 
